\section{P4.132 REDUCING HARASSMENT OF FEMALE SEX WORKERS (FSWS) IN LOW INCOME SETTING: TRIPARTITE APPROACH IN BANGLADESH}

doi:10.1136/sextrans-2013-051184.1029

M B Khan. Save the Children, Dhaka, Bangladesh

Background Female Sex Workers (FSWs) intervention is one of the most focused programmes in Bangladesh. FSWs are socially very much stigmatised and their rights are seriously violated. Police and other law enforcing agencies often raid their settings and put into gaol. But the concerned beneficiaries are reluctant to support them. With supports from HIV activists, some FSWs organised themselves and formed a self help group (SHG). Group members feel more empowered than other general FSWs with increased self esteem. They have started working for protecting their own rights. Being service provider, Save the Children assisted them in installing a tripartite approach through ensuring effective linkage among SHG, lawyers agency and local police which helps FSWs getting access to legal support by their own effort.

Methods In this approach, SHG of FSWs, lawyers agency and local police centre are working together when a sex worker is imprisoned. These three parties have a memorandum of understanding for some activities which will ensure mutual benefit. Selected SHG members will contact with local police centre as well as lawyers focal person when a sex worker is captured. The lawyer agency engages lawyers for getting bail of the sex worker with nominal fee. And the motivated local police person avoid in raiding sex workers setting unnecessarily. Results This tripartite approach has started giving excellent result. It started working in favour of sex workers' community. The self esteems and confidences of sex workers' have significantly increased among FSW community especially in the SHG working area. This also helps changing the attitudes of influential people of the society. Conclusions Any good approach really works if all concerned stakeholders play their role at the right moment and in an appropriate way. This approach is one of the most successful examples in reducing harassments to the FSWs.

\section{P4.133 PERCEIVED INFECTION SOURCE AMONG MEN WHO HAVE SEX WITH MEN (MSM) AND TRANSGENDER WOMEN (TW) RECENTLY DIAGNOSED WITH HIV, SYPHILIS, OR GONORRHOEA/CHLAMYDIA IN LIMA, PERU}

doi:10.1136/sextrans-2013-051184.1030

'C S Blair, 'E R Segura, 'A Perez-Brumer, ${ }^{2} \mathrm{~J}$ Salvatierra, ${ }^{2} \mathrm{~J}$ Peinado, ${ }^{2} \mathrm{~J}$ Sanchez, ${ }^{2} \mathrm{~J}$ R Lama, 'J L Clark. 'David Geffen School of Medicine at UCLA, Department of Medicine and Program in Global Health, Los Angeles, CA, United States, ${ }^{2}$ Asociacion Civil Impacta Salud y Educacion, Lima, Peru

Background Epidemiologic data demonstrates unequal distribution of HIV and STIs among MSM in Peru, with higher risk subpopulations disproportionately affected. Perceptions about partners as source of recent acquired STIs and its correlates could contribute to this epidemic by several mechanisms and serve as basis for future interventions.

Methods 323 MSM and TW from Lima, Peru diagnosed with HIV (45.5\%), Syphilis (53.9\%), and/or Gonorrhea/Chlamydia (15.2\%) within the last month were surveyed to assess partner sexual identity, and perception of most recent sexual partner as source of infection. Prevalence ratios (PR) were calculated using heterosexually-identified partners as the reference category in bivariate and multivariate analysis using partner perceived source of infection as the main outcome.

Results Respondents aged from 18-60 years old (Mean: 30.8, SD: 9.3) and self-identified as Heterosexual (6.0\%), Bisexual (17.1\%), Homosexual (64.8\%), and Transgender (12.1\%). Most recent sexual partners identified as Heterosexual (10.3\%), Bisexual (41.5\%),
Homosexual (45.7\%), and Transgender (2.5\%). Perception of most recent sexual partner as likely/highly likely to be the source of STI transmission was reported by $37.2 \%(N=120 / 323)$ of respondents. Heterosexually-identified partners were least frequently perceived as the source of STI (24.1\% perceived as likely/highly likely source). Transgender partners were most frequently perceived as the source of STI (57.1\% likely/highly likely source; PR = 2.4; 95\% CI: $1.0-5.9$; $\mathrm{p}=0.5)$ followed by Homosexual (45.7\% likely/highly likely source; $\mathrm{PR}=1.9 ; 95 \% \mathrm{CI}: 1.0-3.7 ; \mathrm{p}=0.06)$ and Bisexual (31.6\% likely/ highly likely source; $\mathrm{PR}=1.3$; $95 \% \mathrm{CI}$ : $0.7-2.6 ; \mathrm{p}=0.06$ ) partners, demonstrating a borderline statistical significance.

Conclusions Partner sexual identity is associated with perception of infection transmission among MSM in Peru. Overall, trends in perception mirror the actual gradient of HIV burden across sexual identities. Future research should focus on the exact potential causes for this at the individual-level (actual knowledge of the epidemic, discrimination, actual past experiences, etc.) and contexts (norms, beliefs, etc.).

\section{P4.134 STRATEGIES FOR COMMUNITY SYSTEMS STRENGTHENING IN THE ISEAN-HIVOS PROGRAM TARGETING MSMS AND TRANSGENDERS IN MALAYSIA, INDONESIA, PHILIPPINES AND TIMOR LESTE- AN EVALUATION}

doi:10.1136/sextrans-2013-051184.1031

\section{P Norella. ISEAN Hivos Program, Jakarta, Indonesia}

Background The ISEAN-Hivos Program is a regional HIV-prevention programme targeting MSM and Transgenders. The approach used by the programme is Community Systems Strengthening through the provision of assistance and capacity building for MSM and TG Community Based Organizations (CBOs) in four countries in the South East Asian Region, namely Malaysia, Indonesia, Philippines and Timor Leste. Some of the training activities of the programme include: 1. Workshops for the localization of BCC materials; 2. Training of outreach workers/peer educators on BCC and condom distribution; 3 . Trainings on networking and advocacy; 4. Provision of trainings for network partners to support rollout of monitoring and documentation strategy; and 5. Capacity building for MSM and TG CBOs to participate in UNGASS (or MDG for Health Review) monitoring

Methods An evaluation was conducted after its first year of implementation through a review of strategies that are to be adopted during the first two years of the programme. The evaluation was included in the discussions among the partners of the Program during their inception meetings.

Results Results of the strategic evaluations include:

1. There is a need to synchronise the various activities being implemented at the country level with other regional initiatives of the Program.

2. There is a need to re-cast the approaches of the Program, including the strategies identified in developing CBOs for MSMs and Transgenders especially in under-represented areas in the four countries.

3. There is a need to further examine the complementarity of the regional programme's activities with those of the national programmes, particularly those with funding support from the Global Fund.

Conclusions These results from the early evaluation of the Program provide inputs on the refinement of approaches being used by other HIV prevention programmes targeting MSM and Transgender populations in the region.

\section{P4.135 COMPETITIVE SMALL SCALE HIV FUNDING AS A CATALYST FOR INCREASED MSM AND TG INVOLVEMENT IN LOCAL AND NATIONAL RESPONSES TO HIV-AIDS}

doi:10.1136/sextrans-2013-051184.1032

L P Norella. ISEAN Hivos Program, Jakarta, Indonesia 